\title{
NITRATE FLUCTUATIONS IN ANTARCTIC SNOW AND FIRN: POTENTIAL SOURCES AND MECHANISMS OF FORMATION
}

\author{
by \\ Bruce C. Parker, \\ (Department of Biology, Virginia Polytechnic Institute and State University, Blacksburg, \\ Virginia 24061, U.S.A.)
}

Edward J. Zeller

(Department of Geology, University of Kansas, Lawrence, Kansas 66045, U.S.A.)

\section{and Anthony J. Gow}

(U.S. Army Cold Regions Research and Engineering Laboratory, Hanover, New Hampshire 03755, U.S.A.)

\section{ABSTRACT}

We summarize here data on in situ nitrate ion concentrations in snow pits and firn cores over the last $\sim 3250$ a. Nitrate fluctuations show seasonal, 11 and 22 a periodicities, and long-term changes both at South Pole station and Vostok. High nitrate levels conform to winter darkness and solar activity peaks. Long-term lows and highs conform to solar activity minima and maxima. The data available support the hypothesis that nitrate is fixed in the upper atmos- phere by some solar-mediated phenomenon causing a periodicity in East Antarctica snow. Background levels and non-periodic spikes in nitrate come from other sources.

\section{INTRODUCTION}

For 3 a, we have examined the concentrations of inorganic nitrogenous ions in Antarctic snow and firn from pits and cores (Parker and others 1977, 1978[a], $[b],[c], 1981$, in press, Rood and others 1979,

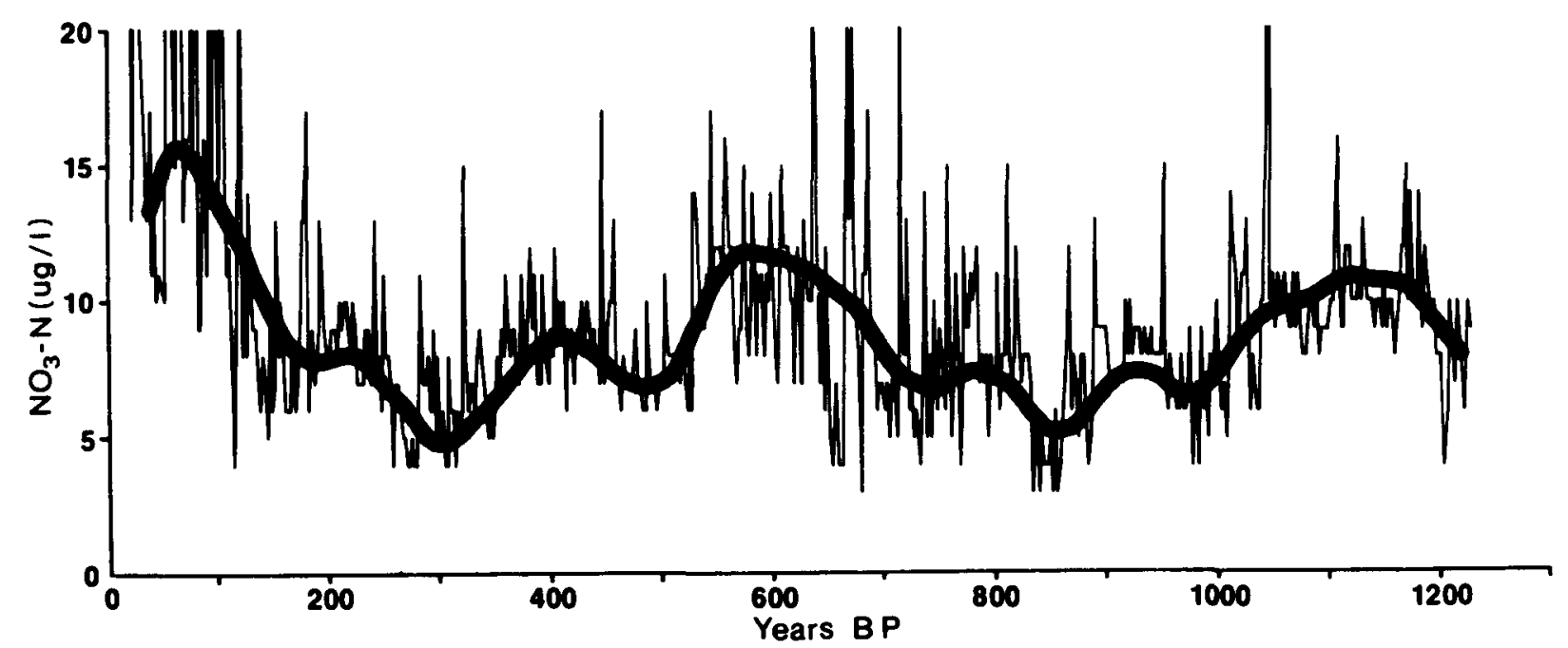

Fig.1. Plot of raw data for nitrate concentration ( $\mu g \ell^{-1}$ as $\mathrm{NO}_{3}-\mathrm{N}$ ) for approximately semiannual accumulation increments of snow in a trimmed $108 \mathrm{~m}$ South Pole firn core collected December 1978. Superimposed upon the raw data plot is a computer-derived cubic spline smoothing function (see text for details) showing major longer-term maxima and minima in the $\sim 1.2 \mathrm{ka}$ of snow. Years BP are approximate, based on average annual accumulation for the century $1850-1750$ from Giovinetto (1960). 
Parker and Zeller 1979, 1980, Zeller and Parker 1979, 1981 , Zeller and others 1981). The data show that the nitrate ion $\left(\mathrm{NO}_{3}{ }^{-}\right.$, hereafter $\mathrm{NO}_{3}$ ) fluctuates (wt/vol) seasonally and in synchrony with the 11 and 22 a periodicity of the solar activity cycle and with the longer solar periodicity of several $100 \mathrm{a}$. We emphasize here this research on $\mathrm{NO}_{3}$ and discuss sources or mechanisms for $\mathrm{NO}_{3}$ fluctuations.

\section{MATERIALS AND METHODS}

Preventing or minimizing contamination of core and snow pit samples during collection, packaging, shipping, processing, and analysis are extremely important. The ultraviolet spectrophotometric analytical procedure for $\mathrm{NO}_{3}$ is the key to our precision and accuracy. These and the computer analytical techniques have been described previously (especially Parker and others 1981, Zeller and Parker 1981).

\section{RESULTS}

Figure 1 shows both the raw data and a cubic spline-derived smoothed curve for the raw data obtained from the $1978108 \mathrm{~m}$ South Pole firn core. The raw data include 1655 separate $\mathrm{NO}_{3}$ analyses. $\mathrm{NO}_{3}-\mathrm{N}$ (as $\mu g \ell^{-1}$ ) ranged from 6.0 to 53.0 with a mean of 22.7. Fourier analysis of the data has disclosed strong periodicities at 11 and 22 a of snow accumulation. In view of the uncertainties in stratigraphic dating of cores, we cannot expect to determine the cyclicity with an accuracy better than $\pm 10 \%$. The cubic spline smoothed curve passing through the raw data brings out the long-term changes in $\mathrm{NO}_{3}$.

Figure 2 shows information comparabie to that of Figure 1, but for a shorter length of Vostok 1979 firn core. Because of lower average annual accumulation and the amount of water required for analyses, the raw data include 598 separate $\mathrm{NO}_{3}$ analyses. $\mathrm{NO}_{3}-\mathrm{N}$ (as $\mu \mathrm{g} \ell^{-1}$ ) ranged from 2.0 to 18.0 with a mean of 8.4 and was significantly lower than values for South Pole. Fourier analysis of the Vostok data also disclosed periodicities at 11 and $22 \mathrm{a}$, in good general agreement with the South Pole data. The smoothed curve passing through the raw data, moreover, has brought out long-term maxima and minima, which are similar in age to those of the South Pole firn core. These smoothed curves have been shown to correlate negatively with Eddy's (1977) $\Delta^{14} \mathrm{C}$ curve based on dated tree rings (Zeller and Parker 1981).

Figure 3 shows raw data and a smoothed curve for the entire $101 \mathrm{~m}$ Vostok firn core, which represents $\sim 3250$ a. Additional maxima and minima are visible throughout the core length.

Other information

Three replicate sets of c. 250 samples, each taken at sequential depths from a $10 \mathrm{~m}$ deep South Pole snow pit during 1980-81, have been completed. Stratigraphic analysis within this pit has permitted the assignment of years for the snow layers. Because a reasonable estimate of the annual snow accumulation can be made, we have calculated our $\mathrm{NO}_{3}$ data as $\mathrm{mg} \mathrm{m}^{-2} \mathrm{a}^{-1}$. The $\mathrm{NO}_{3}$ values are consistent with the levels obtained for the South Pole firn core (Fig.1). However, when calculated as $\mathrm{NO}_{3}-\mathrm{N}$ in $m g m^{-2} a^{-1}$, years with above average snow accumulation show higher $\mathrm{NO}_{3}$ than years with below average accumulation. A plot of the sun-spot numbers for the 50 a period shows a linear correlation coefficient for the $\mathrm{NO}_{3}$ and the sun spots of $0.35(p<0.01)$ and an even better correlation of $0.43 \quad(p<0.001)$ for the aa geomagnetic index with good agreement between all three replicate sets. In contrast, we have obtained very poor correlations between $\mathrm{NO}_{3}$ and $\mathrm{Na}$.

Similar types of correlations result when statistical analyses have been conducted on the raw data from the firn cores. For example, the high levels of $\mathrm{NO}_{3}$ tend to correlate reasonably well with high sunspot numbers, as far as good records can be obtained, and $\mathrm{Na}$ correlates poorly.

While annual dating becomes less accurate with increasing firn core depth, a reasonably close approximation of date can be obtained using Giovinetto's (1960) South Pole data which goes back to AD $1750 \pm 15$ a. By extrapolation backward, using the average annual accumulation of Giovinetto for the century 1850-1750, there is little doubt that the most recent prolonged minimum in $\mathrm{NO}_{3}$ approximates $1710-1645$, the Maunder minimum, a period claimed to be one of few. sun spots and, thus, low solar activity (Eddy 1977).

The data suggest that one or more periodic phenomena result in fairly regular fluctuations in $\mathrm{NO}_{3}$ in Antarctic snows. While there are a number of hypothetical sources and mechanisms of production, at least some can be ruled out and others more strongly supported based on data now available.

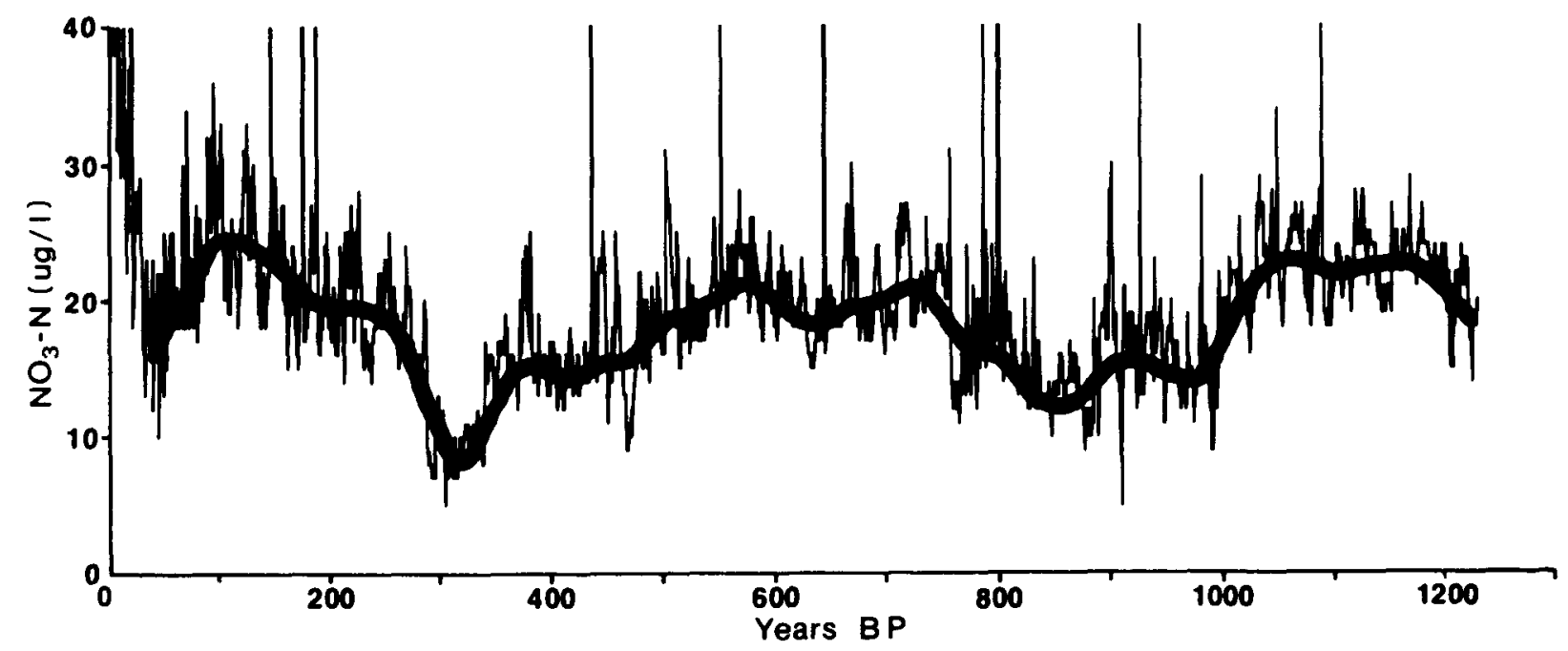

Fig.2. Plot of raw data for nitrate concentration ( $\mu g \ell^{-1}$ as $\mathrm{NO}_{3}-\mathrm{N}$ ) for approximately annual accumulation increments of snow in a trimmed top of a $101 \mathrm{~m}$ Vostok firn core collected December 1979. Superimposed upon the raw data plot is a computer-derived cubic spline smoothing function (see text for details) showing major longer-term maxima and minima in the $\sim 1.2 \mathrm{ka}$ of snow. Years BP are approximate based on average annual accumulation of $22 \mathrm{~mm} \mathrm{a}^{-1}$ water from Barkov and others (1977). 


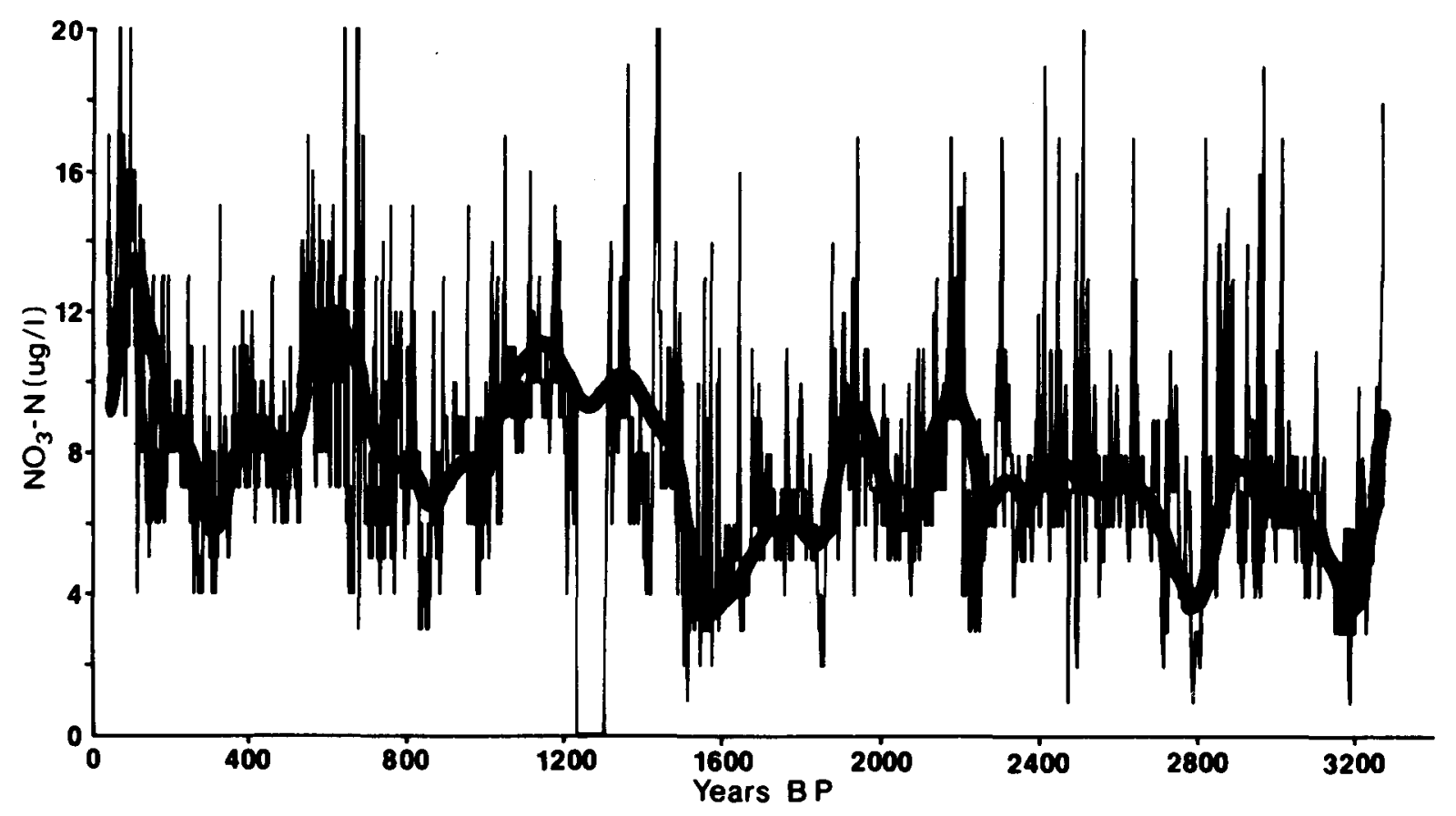

Fig.3. Plot of raw data for nitrate concentration ( $\mu \mathrm{g} \ell^{-1}$ as $\mathrm{NO}_{3}-\mathrm{N}$ ) for approximately annual accumulation increments of snow in a trimmed $101 \mathrm{~m}$ Vostok firn core collected December 1979. Superimposed upon the raw data plot is a computer-derived cubic spline smoothing function (see text for details) showing major longer term maxima and minima in the $\sim 3.25 \mathrm{ka}$ of snow.

\section{DISCUSSION}

Results now available allow evaluation of 14 various hypothetical sources and/or mechanisms for the $\mathrm{NO}_{3}$ ion fluctuations in Antarctic pit snows and firn cores, as proposed by Parker and others (in press).

1. In situ microbiological fixation of $\mathrm{NO}_{3}$

Parker and others (1977) rejected this hypothetical source/mechanism for $\mathrm{NO}_{3}$ production in South Pole snow: (a) viable microorganisms were not culturable from firn or ice-core samples below $3 \mathrm{~m}$ depth; bacteria which were cultured in near-surface South Pole snow were sparse heterotrophic bacteria incapable of producing $\mathrm{NO}_{3}$ ion, (b) visible microbial cells were not detectable by direct microscopic observations of snow and firn core melt water concentrated by filtration, (c) analyses of filtered snow and firn samples for detectable chlorophyll and adenosine triphosphate (ATP) were all negative at approximate detection 1 imits of 100 microscopic algal cells (for chlorophyll) and 1000 bacterial cells (for ATP); such low numbers of cells could account for only a few nanograms of cellular $\mathrm{NO}_{3}$ (Parker unpublished), (d) nitrifying bacteria are now known to metabolize nitrogen readily at low temperatures (Golterman 1975), and nitrifiers are uncommon in Antarctica (e.g. Boyd and others 1966, Benoit and Ha11 1970, Parker and others 1977), and (e) metabolic activity is not possible without liquid water or where temperatures never rise above freezing; thus, South Pole and Vostok with mean annual temperatures of $-50.9^{\circ} \mathrm{C}$ and $-55.6^{\circ} \mathrm{C}$, respectively, cannot have snow with actively metabolizing, $\mathrm{NO}_{3}$ producing microbial life.

2. Contamination from drilling, handling, packaging, storing, shipping and/or processing

Firn-core contamination can occur at essentially every point from drilling to analysis, and our analytical resolution for $\mathrm{NO}_{3}\left(1.0 \mu \mathrm{g} \mathrm{N} \ell^{-1}\right)$ with firn-core values as low as a few $\mu \mathrm{g}$ make contamination a major concern. We have shown, however, that contamination can be minimized or eliminated by: (a) pack- aging core sections in oversized polyethylene tubing to prevent splitting, (b) storing core sections in standard aluminium-lined cardboard core tubes rather than Rutford (polystyrene) core boxes, (c) packing core tubes in clean bulk snow for transit, (d) collecting snow-pit samples some distance upwind of the stations, (e) trimming cores to remove external contamination, (f) logging, if not removing, coresection ends, $(\mathrm{g})$ various analytical procedures, such as testing distilled water blanks each day of analysis, using internal standards (Parker and others 1981). Finally, contamination which is random or general, except perhaps for core ends, should not show cyclicity.

3. Global anthropogenic pollution with tropospheric

\section{transport}

GTobal pollution should come from tropospheric transport from the northern hemi sphere or lower southerly latitudes, across the Southern ocean to East Antarctica. Levels of such pollution should rise with recently deposited snow layers in response to the expansion of human population, and agrarian and industrial societies. Our data give no evidence of such an increase in $\mathrm{NO}_{3}$. The exception is the top $3 \mathrm{~m}$ of snow in the vicinity of South Pole station which most certainly is contaminated locally, such as from the burning of diesel fuel and from other activities since the International Geophysical Year (Parker and others 1977).

4. Soil denitrification with tropospheric transport

The same arguments which ruled out global anthropogenic pollution inputs to East Antarctica apply here. If significant $\mathrm{NO}_{3}$ is derived from soils north of Antarctica, we would expect a detectable rise in levels with the more recent expansion of agrarian and industrial societies, deforestation, and application of $\mathrm{NO}_{3}$ fertilizers. This evidence is lacking. 5. Marine aerosols with tropospheric transport

The mechanisms involving marine aerosol production concern bubbles of gas which form in the turbulent ocean, rise through water, and selectively collect ions, organic matter, detritus, and micro- 
organisms on their surfaces. At the ocean's air/water interface, the bubbles burst creating several smaller jet droplets which carry varying concentrations of substances into the atmosphere as marine aerosols (Blanchard and Parker 1977).

Information on $\mathrm{NO}_{3}$ in marine aerosols is scarce and little research on this subject has been conducted in the Southern Ocean. However, enrichment of trace elements and some other ions in sea salt may be important in precipitation (Duce and Hoffman 1976).

No doubt marine aerosols reach the interior of Antarctica. However, nitrogen oxide compounds have turnover times of only days to weeks in the atmosphere (Söderlund 1977), so much $\mathrm{NO}_{3}$ should fall out before reaching South Pole station or Vostok. Furthermore, higher input during the austral summer when a greater mass of circumpolar water is ice-free and subject to aerosol production might be expected.

Evidence that marine aerosols are not significant sources of $\mathrm{NO}_{3}$ include (a) the poor correlation between $\mathrm{NO}_{3}$ and $\mathrm{Na}$ in our South Pole snow pit (i.e. 0.21 based on $c .750$ data points), and (b) the lack of enrichment of $\mathrm{NO}_{3}$ relative to $\mathrm{Na}$ in both Antarctic and temperate marine aerosols (Parker and others unpublished). Thus, while input of marine air to the East Antarctic ice sheet is undeniable, the $\mathrm{NO}_{3}$ input of marine origin cannot be significant and cannot be responsible for the observed $\mathrm{NO}_{3}$ fluctuations.

6. Fixation by lightning with stratospheric transport

Lightning produces some $\mathrm{NO}_{x}$, but the total amounts fixed are considered smal1; lightning storms also do not occur at high latitudes (Delwiche 1977). Thus, any contribution to the $\mathrm{NO}_{3}$ of Antarctic snow from 1 ightning would require stratospheric transport and such would not occur over the Antarctic ice sheet. Also, the bulk of $\mathrm{NO}_{3}$ fixed in the troposphere is washed out rapidly (Söderlund 1977). In addition, one might expect the $\mathrm{NO}_{3}$ levels to be higher during the austral summer when convective storms propagate in the southern hemisphere. The $\mathrm{NO}_{3}$ data for Antarctic snow gives no support for a significant contribution from lightning.

\section{Volcanic activity with stratospheric transport}

$\mathrm{N}_{2} \mathrm{O}_{3}$ has been reported in volcanic gases (Miyak $1965)$ so a contribution of $\mathrm{NO}_{3}$ from volcanic activity is possible as an occasional non-periodic pulse. The most likely sources are volcanoes associated with Antarctica, such as Mt Erebus, which is c. $1400 \mathrm{~km}$ from South Pole. The existence of a south polar vortex as a stable atmosphere feature implies further than any volcanic emanations from great distance would have to reach the Antarctic ice sheet through the stratosphere. Thus, only large eruptions that penetrate the tropopause should influence the $\mathrm{NO}_{3}$ levels in Antarctic snow. Indeed, the bottom of our 101 m Vostok firn core contains a layer of volcanic ash derived from a presently unidentified volcanic source and event ( $P R$ Kyle personal communication). The bulk of $\mathrm{NO}_{3}$ cannot be of volcanic origin. This is further supported by the 11 and 22 a cyclicity of $\mathrm{NO}_{3}$.

\section{Fixation by meteoroid trails in the strato-}

\section{sphere}

Meteoroids enter the atmosphere over Antarctica, and therefore may produce some $\mathrm{N}_{3}$, a small amount of which would fall out from the upper atmosphere. Thus, meteoroids provide a sinall continuous source of $\mathrm{NO}_{3}$ (Park and Menees 1978).

\section{Photochemical (UV) fixation in the stratosphere}

Stratospheric photochemical fixation is a probable source of some of the $\mathrm{NO}_{3}$ in Antarctic snow. If this were a major mechanism, $\mathrm{NO}_{3}$ would be produced only during the light period and a seasonal high for $\mathrm{NO}_{3}$ might occur near the end of the austral summer. Our $\mathrm{NO}_{3}$ data, however, do not support this mechanism, because the higher $\mathrm{NO}_{3}$ concentrations appear to occur near the end of the austral winter.
10. Ionization in upper atmosphere by galactic cosmic

\section{rays}

Galactic cosmic rays probably contribute a small portion of the total $\mathrm{NO}_{3}$ in Antarctic snow. These MeV and GeV energy-level rays should penetrate the upper atmosphere to $>30 \mathrm{~km}$ altitude, whence $\mathrm{NO} \times$ produced would survive photochemical destruction (Bauer 1978). However, galactic cosmic ray fluxes are highest in the Eartin's atmosphere when solar activity is lowest. Thus, any major $\mathrm{NO}_{3}$ signal produced by galactic cosmic rays should be out of phase with the solar activity peak period. Our higher $\mathrm{NO}_{3}$ values more or less corresponding to solar activity peaks is strong support that galactic cosmic rays probably contribute only a small fraction of the $\mathrm{NO}_{3}$ to Antarctic snow. Furthermore, the Maunder minimum, which was a prolonged period of low solar activity when one would expect higher galactic cosmic ray fluxes to Earth (Eddy 1977, Lin 1977), corresponds in our firn cores to lower $\mathrm{NO}_{3}$ values.

11. Ionization in the upper atmosphere by solar cosmic rays

Possib7y the component of the $\mathrm{NO}_{3}$ signal which generaliy coincides with the solar activity peak relates to solar cosmic rays. Solar cosmic rays should penetrate the Earth's atmosphere to $>50 \mathrm{~km}$ altitude where photochemical destruction of $\mathrm{NO}_{3}$ should be reduced. Also, the Maunder minimum may have been a period of lower solar cosmic ray fluxes and lower $\mathrm{NO}_{3}$ production.

12. Ionization in the upper atmosphere by auroral activity and by polar cap absorption

Wilson and House (1965) reported nitrate and nitrite in a composite South Pole snow sample and suggested the aurora as the most probable source. Jones (1974) has reviewed the auroral mechanisms for the production of $\mathrm{NO}_{\mathrm{x}}$. Aurorae occur when protons from solar flares reach the Earth's atmosphere. These protons, normally having energies of 1 to $>100 \mathrm{keV}$ (Aikin and Bauer 1968), penetrate to 60 to $90 \mathrm{~km}$ altitude but are more plentiful than the galactic Cosmic rays. Nicolet (1970) considers that some $\mathrm{NO}_{x}$ produced at these altitudes can reach the ground. Crutzen (1971) adds that, since the conversion to $\mathrm{NO}_{3}$ occurs mainly during the night, appreciable quant$i$ ties at high latitudes may be produced during winter.

Associated with aurorae are downward ionization fluxes called Bremstrahlung $x$-rays. These penetrate below $50 \mathrm{~km}$ altitude where photochemical destruction is further reduced.

These points suggest that some of the $\mathrm{NO}_{3}$ detectable in the South Pole firn core may come from auroral fixation at high altitudes. This suggestion is supported by the greatly reduced $\mathrm{NO}_{3}{ }^{-}$during the period approximately coincident with the Maunder minimum and by the 11 a cyclicity in $\mathrm{NO}_{3}$ and solar activity (Eddy 1977).

We also note the $\mathrm{NO}_{3}$ data for South Pole station and Vostok cores. Short- and longer-term fluctuations were apparent in both cores, but the $\mathrm{NO}_{3}$ levels were lower at Vostok. The discrepancy is greater if one calculates annual $\mathrm{NO}_{3}$ fallout, because the annual accumulation is much less at Vostok than South Pole station. Due to the Earth's geomagnetic field, the aurorae are most intense in a toroidal shaped pattern which passes close to the South Pole and is centered on Vostok (0mholt 1971). Therefore, if $\mathrm{NO}_{3}$ precipitates as particulate material and fallout is rapid, the lower levels of $\mathrm{NO}_{3}$ in the Vostok core may be the result of lower upper atmospheric $\mathrm{NO}_{3}$ produced. 13. Ionization in the upper atmosphere by solar flares

A contribution to the $\mathrm{NO}_{3}$ by solar flares remains probable both for the background signal and the $\mathrm{NO}_{3}$ spikes. The energetic particles would penetrate deeply into the atmosphere in polar regions. However, a correlation with solar activity is not obvious. Flares tend to precede and follow peaks of solar activity but do not coincide with them ( $L$ in 1977). 
Very high $\mathrm{NO}_{3}$ peaks not attributed to end core section contamination might be caused by giant solar flares, as suggested by Stothers (1980).

14. Ionization in the upper atmosphere by supernovae Relative to volcanic activity, meteoroid trails, photochemical fluctuations, galactic cosmic ray fluxes, and solar activity cycles, such as solar cosmic rays, aurorae, and/or solar flares, supernovae are rare and non-periodic (Rood and others 1979). Nevertheless, it remains possible that a few of our very high $\mathrm{NO}_{3}$ peaks might be the result of ionization in the upper atmosphere by $x$ - or $y$-rays from supernovae nearby in the galaxy.

\section{CONCLUSIONS}

of 14 hypothetical sources or mechanisms for the levels and fluctuations of $\mathrm{NO}_{3}$ in Antarctic snow and firn, virtually all which entail ground level or tropospheric transport phenomena, as well as lightning fixation with stratospheric transport, have been ruled out, using direct and indirect support. While not excluded from consideration, volcanic activity, supernovae, fixation by meteoroid trails, and galactic cosmic rays can contribute only occasional pulses (the first two) or low level background $\mathrm{NO}_{3}$ (the last two). We are left, thus, with four solar-mediated sources/mechanisms to explain the $\mathrm{NO}_{3}$ fluctuation in snow of the East Antarctic plateau: photochemical ultraviolet production, ionization in the upper atmosphere by solar cosmic rays, auroral activity and polar cap absorption, and solar flares. Based on data presently available we conclude that the $\mathrm{NO}_{3}$ in snow, firn, and ice of East Antarctica is produced by more than one mechanism. Some solar-mediated mechanism closely tied to the 11 a solar maximum and alternating 11 or 22 a solar magnetic field reversal probably is responsible for the 11 and 22 a periodicity in $\mathrm{NO}_{3}$. This overlies a background level and is periodically interrupted or masked by major nitrate spikes. A working hypothesis uses a minimum of three mechanisms: galactic cosmic rays for background, solar-mediated aurorae for the 11 a cyclicity, and giant solar flares for $\mathrm{NO}_{3}$ spikes.

our search to identify the mechanism(s) has been narrowed. Apparently we have discovered a chemical fingerprint for past solar activity in Antarctic snow, but not necessarily a fingerprint for past global climate. This fingerprint, while differing quantitatively between South Pole and Vostok, is nevertheless present in both locations and in several cores and snow pits from South Pole, suggesting that it probably occurs in much of the Antarctic ice sheet.

\section{REFERENCES}

Aiken A C, Bauer S J 1968 The ionosphere. In Hess W N, Mead G D (eds) Introduction to space science. New York, Gordon and Breach: 133-178 Barkov N I, Korotkevich E S, Gordienko F G, Kotlyakov VM 1977 The isotope analysis of ice cores from Vostok station (Antarctica), to the depth of $950 \mathrm{~m}$. International Association of Hydrological Sciences Publication 118 (General Assembly of Grenoble 1975 - Isotopes and Imourities in snow and (ce) $: 382-387$

Bauer $E$ 1978 Non-biogenic fixed nitrogen in Antarctic surface waters. (Matters arising). Nature 276(5683): 96

Benoit RE, Hall C L Jr 1970 The microbiology of some dry valley soils of Victoria Land, Antarctica. In Holdgate MW (ed) Antaretic ecology, Vol. 2. London and New York, Academic Press: $697-701$

Blanchard D C, Parker B C 1977 Water-to-air transfer of microorganisms and organic matter. In Cairns J C Jr (ed) Aquatic microbial communities. New York, Garland: 625-658
Boyd W L, Staley J T, Boyd J W 1966 Ecology of soil microorganisms of Antarctica. In Tedrow J C F (ed) Antaretic soils and soil forming processes. Washington, DC, American Geophysical Union: 125-159 (Antarctic Research Series 8)

Crutzen P J 1971 Ozone production rates in an oxygen-hydrogen-nitrogen oxide atmosphere. Joumal of Geophysical Research 76(30): 7311-7327

Delwiche $C \dot{C} 1977$ The nitrogen cycle. Soientific American 222: 137-146

Duce $R A$, Hoffman $E J 1976$ Chemical fractionation at the air/sea interface. Annual Review of Earth and Elanetary Sciences 41: 187-228

Eddy J A 1977 Climate and the changing sun. Climatic Change 1(2): 173-190

Giovinetto M B 1960 USNC-IGY Antarctic glaciological data; field work 1958 and 1959. South Pole station. Ohio State University Research Foundation, Project 825, Report 2, Part 4

Golterman H L 1975 Physiological Limnology. New York, Elsevier

Jones A V 1974 Aurora. Dordrecht and Boston, D Reidel (Geophysics and Astrophysics Monographs 9)

Lin R 1977 Energetic particles from the sun and solar modulation of galactic cosmic rays. In White O R (ed) The solar output and its variation. Boulder, CO, Colorado Associated University Press: 39-47

Miyake Y 1965 EZements of geochemistry. Tokyo, Maruzen

Nicolet M 1970 The origin of nitric oxide in the terrestrial atmosphere. Flanetary and space Seience 18: 1111-1118

Omholt A 1971 The optical aurora. Berlin etc, Springer-Verlag

Park C, Menees G P 1978 Odd nitrogen production by meteoroids. Joumal of Geophysical Research 83(8): 4029-4035

Parker B C, Zeller E J 1979 Nitrogenous chemical composition of Antarctic ice and snow. Antaretic Joumal of the United States 14(5): 80-82

Parker B C, Zeller E J 1980 Nitrogenous chemical composition of Antarctic ice and snow. Antareti: Journaz of the United States 15(5): 79-81

Parker B C, Zeller E J, Heiskel1 L E, Thompson W J 1977 Nitrogen in south polar ice and snow: tool to measure past solar, auroral, and cosmic ray activities. Antaretic Journal of the united States 12(4): 133-134

Parker B C, Zel ler E J, Harrower K, Thompson $W \mathrm{~J}$ 1978[a] Fixed nitrogen in Antarctic ice and snow. Antaretic Joumal of the united States 13(4): 47-48

Parker B C, Heiskel1 L E, Thompson W J, Zeller E J 1978[b] Non-biogenic fixed nitrogen in Antarctica and some ecological implications. Nature 271(5646): 651-652

Parker B C, Heiskell L E, Thompson W J, Zeller E J 1978[c] Non-biogenic fixed nitrogen in Antarctic surface waters. (Matters arising). Nature 276(5683): $96-97$

Parker B C, Thompson W J, Zeller E J 1981 Evaluation of ultra-violet spectrophotometric determination of nitrate-nitrogen in glacial snow, firn and ice. Analyst 106:898-901

Parker B C, Zeller E J, Gow A J In press. Nitrogenous chemical composition of Antarctic ice and snow. Antaretic Joumal of the United States

Rood R T, Sarazin C L, Zeller E J, Parker B C 1979 $A$ possible record of $\gamma$ - and/or $x$-rays from supernovae. Nature 282: 701-702

Söderlund R 1977 Nox pollutants and ammonja emissions - a mass balance for the atmosphere over NW Europe. Ambio 6: 118-122

Stothers R 1980 Giant solar flares in Antarctic ice. Nature 287: 365

Wilson A T, House D A 1965 Fixation of nitrogen by aurora and its contribution to the nitrogen balance of the earth. Nature 205(4973): 793-794 
Parker and others: Nitrate fluctuations in Antaretic snow and firm

Zeller E J, Parker B C 1979 Solar activity

records. Planetary ice caps. In Anderson D M

(ed) Proceedings of the Second Colloquium on

planetary Water and Polar Processes, October 1978.

Hanover, NH, US Army Cold Regions Research and

Engineering Laboratory: 186-192

Zeller E J, Parker B C 1981 Nitrate ion in

Antarctic firn as a marker for solar activity.

Geophysical Resecrch Letters 8: 895-898

Zeller E J, Parker B C, Gow A J 1981 Planetary and

extraplanetary event records in polar ice caps.

In Anderson D M (ed) Proceedings of the Third

Colloquium on Interplanetary Water, October 1980.

Buffaio, NY, State University of New York: 18-27 